\title{
Developing Speaking Skills on EFL Learners through Biography-Driven Instructional Strategies
}

\author{
María Luisa Vire ${ }^{1 *} \quad$ Tammy Fajardo ${ }^{2}$ \\ 1.Unidad Educativa del Milenio Bernardo Valdivieso, Loja, Ecuador \\ 2.Faculty of Philosophy, University of Cuenca, Ecuador \\ *E-mail of the corresponding author: maluisavire0409@gmail.com
}

\begin{abstract}
This mixed-method case study evaluated the effectiveness of Biography Driven Instructional (BDI) strategies in developing EFL learners' speaking skill. The participants of the study included 23 students from a high school in Loja, south of Ecuador. Data were collected through interviews as pre and post tests and a focus group. Findings from descriptive and inferential analysis show a statistically significant difference in pre-post speaking tests and participants' perceptions revealed that the use of these strategies had a positive effect on their oral skills. It was concluded that BDI strategies were found to be beneficial to improve EFL learners' speaking performance after the integration of these tools in the classroom. Implications for teaching and future BDI application are also discussed.
\end{abstract}

Keywords: Biography-Driven Instruction, BDI strategies, speaking skills, EFL learners

DOI: $10.7176 / \mathrm{JEP} / 13-3-01$

Publication date: January $31^{\text {st }} 2022$

\section{Introduction}

Speaking is considered as one of the most useful skills for communication and interaction (Akkaya, Yilmaz \& Aydin, 2018). This skill involves producing, receiving and processing information to construct meaning (Brown, 1994; Burns \& Joyce,1997). Speaking is the first step to certify that someone knows a language and this is shown by being able to have a conversation in the target language (Al-Sobhi \& Preece, 2018). Accordingly, speaking is a fundamental element of any language, and it is the foundation for students' ability to listen, write, and read (Afrazl, Taghizade \& Taghinezhad, 2017). Despite the importance attributed to speaking, it is the most difficult skill to master in EFL settings (Afrazlet al., 2017) because it takes place in actual time (Nunan, 2003). Consequently, teaching and learning how to speak challenges both instructors and EFL students.

In recent years, several studies have reported the difficulties EFL learners encounter when trying to speak English. Dil (2009) argues that anxiety and unwillingness are the two biggest problems concerning learners when speaking because they are afraid, they will receive negative comments when they make mistakes. Likewise, AlSobhi and Preece (2018) mention a number of problems that prevent students from speaking English: learners' lack of motivation and confidence, anxiety, limited English knowledge, ineffective teaching methodology, and lack of exposure to the target language. Most of the aforementioned problems are related to affective factors. Thus, the need to assist learners with their feelings and affects is pivotal to improve their speaking competence.

In this context, the current study reports the effectiveness of implementing the Biography Driven Instruction (BDI) model with its related Biography Driven Instructional strategies in developing the learners' speaking ability at a high school in Loja. The motivation of this study laid in assisting teachers and students from the target institution to overcome the difficulties they face when developing the speaking ability. Furthermore, a search in the literature revealed that there are few studies on the application of BDI strategies in the Ecuadorian context and none of them have been conducted to develop specific language skills such as speaking. Hence, this study sought to evaluate the influence of BDI strategies on the development of EFL students' speaking competence. To address the general and specific objectives, the research question of this study is how the integration of BDI strategies influences students' speaking skills.

Research to date shows the benefits of implementing the social constructivist BDI method (Murry, Holmes \& Kavimandan, 2020) and its related BDI strategies in the classroom. Previous studies using BDI strategies have been conducted to support teachers and students' performance; however, they have not been linked to developing one particular skill. Based on this observation, this mix-method case study was designed to evaluate the effectiveness of BDI strategies to foster speaking. To meet the objectives of the study, quantitative and qualitative data were collected from 23 participants by means of pre-post tests and a focus group respectively. Pre-post tests were administered to analyze participants' entry and exit level. To evaluate students' perceptions toward BDI strategies in the classroom, the researcher conducted a focus group interview.

\section{Literature Review}

Regarding teaching methods, strategies, and activities, there is extensive research investigating different tools to enhance speaking on EFL students. Wang (2014) suggested a four-step pedagogical method for oral lessons of 
Chinese students: Pre-speaking, while speaking, post-speaking, and extension practice as a method to develop fluency and accuracy. Likewise, Daif-Allah and Khan (2016) conducted research to affirm that Open Discussion Sessions are effective to improve oral communicative abilities. Moreover, Afrazl et al. (2017) suggested that using visual aids has a positive effect on learners' speaking proficiency. In addition, Montaño (2017) used learning strategies to improve students' English performance. Some of these strategies are part of the Biography-Driven Instruction model (BDI).

The BDI model has its foundation on studies and theories belonging to those who have devoted their careers to second language acquisition and learning. Some of these concepts or theories are learning strategies, culturallyresponsive teaching, input hypothesis, funds of knowledge, the zone of proximal development, differentiated instruction, among others (Perez, Holmes, Miller, and Fanning, 2012).

The core of BDI (Herrera, 2010) is to consider students' background knowledge, create a safe ecology that enhances development from the known to the unknown, and provide learners with opportunities to demonstrate what they have learned. The BDI model uses four dimensions: sociocultural, linguistic, academic, and cognitive of Culturally and Linguistically Diverse (CLD) learners which guide and promote linguistic and academic development (Perez et al., 2012). Herrera, Kavimandan, and Holmes (2011) proposed a framework of three lesson phases: activation, connection, and affirmation, which apply the principles of the BDI model to promote linguistic and academic development.

Herrera et al. (2011) created a set of Biography-Driven Instructional strategies to enhance high-school teachers' capability to execute the principles of the BDI method (Perez et al., 2012). BDI strategies are social affective, cognitive, and metacognitive tools designed to develop academic vocabulary through the four linguistic skills: reading, listening, writing, and speaking (Herrera et al., 2011). These strategies allow teachers to scaffold instruction as well as capitalizing students' biographies to advance content learning and academic language acquisition. In addition, by using these strategies, learners develop their social and interpersonal skills since they promote pair and group work (Montaño, 2017). According to Herrera et al. (2012), BDI strategies allow educators to use grouping and scaffolding purposely to ensure that all learners are accounted for learning. Each strategy is enforced across the three phases of the lesson activation, connection, and affirmation (Herrera et al., 2012).

Perez et al. (2012) examined the use of BDI strategies with teachers from secondary and elementary schools. A significant difference was found between grade levels in the no strategy condition in elementary-school teachers rather than high-school teachers. Results showed a large effect in classes where teachers use the 19 different BDI strategies that were previously instructed. Both elementary and high-school teachers were supported by the use of BDI strategies to improve their teaching instruction.

MacDonald, Miller, Murry, Herrera, and Spears (2013) explored the effectiveness of the Biography-driven approach to address CLD students in science education. Their aim was to test if teachers who implemented activation, connection, and affirmation (ACA) strategies showed a high level of understanding their culturally responsive practices. Researchers observed both science $(n=14)$ and math $(n=25)$ teachers' classes. The first class was in the no-strategy condition and the second one with the strategy condition. The findings showed that there is a predominant effect on the strategy condition classes rather than the no-strategy condition.

Montaño (2017) conducted a study related to learning strategies in second language acquisition to inform readers about the importance of those strategies in accelerating and facilitating the English learning process. Based on the biography-driven instruction model, the researcher put into practice four BDI strategies to demonstrate their effectiveness in L2 classrooms. After the treatment, the researcher concluded that BDI strategies are effective and adaptable for large classes. Also, she argues that the strategies help students document their knowledge in an environment rich of autonomy, motivation, discussions, and interactions.

Espinosa and Soto (2018) examined two non-traditional pre-assessment tools: Biography Cards and Linking Language BDI strategy to obtain relevant information about students' background. The results showed that allowing students to connect their background to the lesson, using vocabulary and hand-on activities, providing L1 support, and using guarded vocabulary led to learning the target language.

In a more recent study, Murry et al. (2020) investigated teachers' perspectives about the use of the BDI method. This qualitative case study was conducted with four participants from two schools. The data resulted in five themes regarding the effectiveness of BDI; one of the themes determined that using BDI strategies promotes students' engagement. Overall, the BDI model was found to be a potential support for instructors who teach CLD and other students.

\subsection{Statement of the Problem}

The speaking skill is a challenging ability for both EFL teachers and students in Ecuador, where Spanish is its mother tongue. Among the problems EFL learners face when attempting to use English orally are: anxiety, fear of making mistakes, and lack of confidence and motivation (Dil, 2009; Al-Sobhi \& Preece, 2018). In the Ecuadorian context, the lack of English exposure and opportunities to use the foreign language (Jaramillo \& Solano, 2019), lack of interaction, limited and ineffective teaching strategies adopted by instructors to allow the use of English 
(Calle, Calle, Argudo, Moscoso, Smith \& Cabrera, 2012), and low motivation when making mistakes at the moment of speaking (Ochoa, Cabrera, Quiñónez, Castillo, \& González, 2016) are some constraints learners have in regards to the speaking ability.

Previous studies have proposed a wide range of speaking strategies and activities to help EFL learners speak English, yet not all of them have been successful. Speaking issues are the current affair for students from the target public high school located in Loja. This is because many strategies do not address the affective factors that prevent students from feeling anxiety, fear or demotivation at the moment of communicating in English. In such circumstances, it is pivotal to assist learners with their affects and feelings to improve their speaking performance. Therefore, the rationale of this study attempts to improve EFL learners' speaking skills from a public high school through the integration of BDI strategies which have been proved to be cognitive, metacognitive, and social affective tools (Herrera et al., 2011) that execute the principles of the biography-driven instruction model (Herrera et al., 2012) which is located in the communicative and cognitive approaches of content and language acquisition (Herrera, 2016). The BDI strategies facilitate students' active interaction with academic content, vocabulary, and activities to promote learning in a low-risk environment (MacDonald et al., 2013).

Many studies have been conducted to evaluate the use of a variety of strategies and their impact on the development of speaking skills in EFL classrooms; however, studies focusing exclusively on the development of the oral competence implementing BDI strategies have not been conducted yet. In fact, minimal research has been conducted on the BDI model and its strategies in Ecuador. BDI strategies are meant to develop academic vocabulary through reading, listening, writing, and speaking (Herrera et al., 2011); nevertheless, the researcher's focus is on increasing EFL learners' communicative abilities using four BDI strategies: DOTS Chart, Vocabulary Quilt, Pictures and Words, and It's All on My Clipboard. Despite the persistent need to see students communicating with others in English, no study has been conducted before on this topic. Thus, in response to this gap, this study seeks to examine how the integration of BDI strategies influences students'speaking skills. According to the researcher's view, this promising intervention using the BDI model and its strategies will make a considerable contribution to English educational research, teachers, and students.

\section{Methodology}

\subsection{Research Approach and Design}

The researcher applied a mixed-methods approach to evaluate the effectiveness of BDI strategies on EFL learners to develop speaking skill. The intent of a mix methods approach is to combine both quantitative and qualitative data to gain a clearer view of the research problem, and to validate one data with another (Creswell \& Guetterman, 2019 , p. 550). For the quantitative part, the study used a quasi-experimental procedure as the group of study was not randomly assigned (Creswell, 2014, p. 215). To achieve the desired goals, the quantitative data collection instrument was semi-structured interviews to evaluate the speaking ability as pre and post-tests. For the qualitative part, the researcher conducted a focus group interview with unstructured, open-ended questions (Creswell, 2014, p. 239). Since the researcher's focus was to analyze one specific or particular subject or setting (Bogdan \& Biklen, 2007), a case study design was selected. A case study is a detailed examination of a bounded system (e.g., event activity, process, or individuals) which is based on a broad data collection (Creswell \& Poth, 2018). More specifically, this research adopted a mixed methods case study in which "the quantitative and qualitative data collection, results, and integration are used to provide in depth evidence for a case(s) or develop cases for comparative analysis" (Creswell \& Plano Clarke, 2018,p.116).

\subsection{Participants}

Participants of the study were 25 female and male EFL learners with an average age of 16 . They were all in the second year of Bachillerato General Unificado from a public high school located in Loja in the south of Ecuador. The selection process for participants was nonrandom (Creswell, 2014, p. 215) as the group was one of the six groups assigned to the researcher by the authorities at the beginning of the school year. Before the treatment began, participants and their parents were explained the objective of the study, and they were asked to sign an informed consent letter.

\subsection{Treatment}

The researcher selected 4 of the more than 20 BDI strategies (Herrera, 2010; Herrera et al., 2011). The selected strategies were: Vocabulary Quilt, Topic in Pictures and Words, DOTS Chart and It's All on My Clipboard. Before the treatment began and in order to get to know the group of participants, they were asked to complete a student's biography card as part of the process. This card collects information about students' personal information: age, place of birth, preferences, students' cognitive, linguistic, sociocultural and academic background, and students' preferred grouping (Espinosa \& Soto, 2018).

All four BDI strategies were applied throughout the lesson in three stages. The activation stage, in which students activated their previous knowledge by writing down what they knew about the target topic, and then they 
shared their first thoughts or ideas with their classmates. In the connection stage, the researcher was a facilitator and the participants' knowledge was constructed considering what learners have shared in prior interventions, aiming to connect the known to the unknown, and engaging students in different reading, speaking, listening, and writing activities performed in groups or in pairs to confirm and/or disconfirm students' previous predictions about the topic. The affirmation stage allowed the researcher to use authentic assessment. This assessment required students to apply what they learned from others, from the teacher, and from themselves throughout the lesson by documenting their content and language progress (Herrera et al., 2012).

The BDI strategies application included 32 hours of instruction. The topics were chosen by the researcher based on the participants' syllabus. The BDI strategies, topics, and periods were covered as follows:

Table 1. Application of the BDI strategies

\begin{tabular}{lll}
\hline BDI strategy & Topic & Periods \\
\hline Vocabulary Quilt & Healthy And Unhealthy Habits & 8 \\
Topic in Pictures and Words & What You Eat & 7 \\
DOTS Chart & Character And Personality Traits & 9 \\
It's All on My Clipboard & Festivals And Traditions & 8 \\
\hline
\end{tabular}

All sessions, topics, activities, and periods were registered in a research planning schedule sheet adapted from Leedy and Ormrod (2005).

\subsection{Data collection}

\subsubsection{Quantitative}

With the purpose of assessing learners' entry and exit English level, the speaking section, part one of the Key English Test (KET) was selected for the pre and post-test of the study. In part one of the KET exam, each participant interacts with the interlocutor (Askari \& Langroundi, 2014) using basic language with factual information and personal topics. The pre-test was administered before the researcher's intervention to measure students' speaking entry level. The test consisted of an interview with 8 open-ended questions based on topics from the KET Cambridge exam, speaking section, part 1 (see Appendix A). After 32 hours of treatment, participants were administered a post-test to evaluate students' exit level. The questions were similar to the pretest in terms of English difficulty level, time, and number of items. Participants responded to open-ended questions about familiar topics and factual information. Questions were asked based on the speaking section, part one of the KET Cambridge exam (see Appendix B). Participants' responses from pre and post-tests were scored based on the KET Cambridge exam rubric (see Appendix C). The rubric has 5 bands, being 0 the lowest and 5 the highest level of speaking performance (Soria \& Iza, 2019).

The scores from pre and post-tests were documented in an Excel spreadsheet, and then exported into SPSS 22.0. The performance of each participant was measured by two raters. To measure the degree of correlation, and to evaluate the degree of agreement between the two raters, the Intraclass Correlation Coefficient (ICC) was used. According to Koo and Li (2016) "the ICC is a reliability index that reflects both degree of correlation and agreement between measurements." This ICC is used to evaluate different types of reliability: interrater, test-retest, and intrarater reliability of measures (Koo \& $\mathrm{Li}, 2016)$.

3.3.2 Qualitative

To evaluate students' perceptions towards the use of BDI strategies, a focus group interview was carried out, at the end of the treatment. This focus group interview involved 6 interviewees (Creswell, 2014, p. 239) who were randomly selected. To conduct the interview, the researcher used a small number of open-ended questions to elicit responses, and encourage all participants in the group to take their turn to speak (Creswell \& Guetterman, 2019, p. 218). The researcher designed an interview protocol which describes the instructions for the focus group interview process (see Appendix D). The interactions from this focus group were recorded, transcribed into text data (Creswell \& Guetterman, 2019, p. 239), and translated for data analysis purposes. The interview lasted about 30 minutes and was conducted in Spanish. It was necessary to ask a bilingual colleague, whose mother tongue is English, to validate the translation of the interview and reduce subjectivity. This process entailed checking and rechecking the transcripts, and translated interpretations to have more credibility in the results (Lyons \& Coyle 2007). Both the researcher and the bilingual colleague negotiated similar interpretations so that the Spanish interview is accurately equivalent to English.

\subsection{Data analysis}

3.4.1 Quantitative data from pre and post-tests

Both descriptive statistical results and inferential statistical results were generated from the SPSS software. Descriptive statistics are expressed in Means (X) and Standard deviations (SD). The inferences were generated to measure both the degree of correlation and the agreement between measurements of the two raters with the Intraclass Correlation Coefficient (ICC). In this type of reliability, values higher than 0.80 are considered good (Koo \& Li, 2016). The study used Wilcoxon test (Güvendir, Kocabiyik, \& Dündar, 2020) for the non-normal 
distribution, and Student t-Test for the normal distribution (Field, 2013) to establish the significance of the difference between pre and post-tests.

3.4.2 Qualitative data.

To interpret participants' perceptions towards the implementation of BDI strategies in the classroom, the study utilized the ATLAS.ti 7 software (Woolf \& Silver, 2017). The codes were counted by taking the frequency of appearance of the codes. The codes or subcategories were organized to make up a larger organization called the code family (or category) (Charmaz, 2014, p.308). For didactic purposes, codifications are equivalent to categorizations. The categories are in two or three levels depending on the groupings or sets of categories and relationships established. The central category encompasses the detached categories and, in turn, they encompass some subcategories, as detailed below.

The process of coding resulted in the following categories or subcategories: DOTS Chart, Vocabulary Quilt, It's All on My Clipboard, Methodology, Interest, Listening, and Speaking. These were also analyzed by establishing relationships of similarity, difference, and equality, as well as causality to give rise to a code family also called central category labeled as Biography Driven Instructional Strategies. The software ATLAS.ti 7 software (Woolf \& Silver, 2017) allowed the researcher to build a semantic network of the main category by explaining the number of citations that supports the categories and subcategories and the number of connections among them (see Figure 1). Direct quotations were used to ensure the transferability of the categories (Güvendir et al., 2020).

\section{Results \\ 4.1 Quantitative results}

Pre-test reliability. Table 2 shows the mean and standard deviation of the pre-test administered to 23 students, according to the two raters. To establish an initial average measurement of the pre-test, an ICC reliability statistical test was used. The results of the ICC in all cases show reliability higher than $80 \%$ (ICC $>0.80$ ), so it is appropriate to have a single pre-test indicator (a mean between both of the two raters). The results show that the level of grammar and vocabulary has a value of 2.41 points $(\mathrm{SD}=1.37)$; on the other hand, pronunciation has 2.70 points $(\mathrm{SD}=1.39)$, and finally, interactive communication obtained 2.30 points $(\mathrm{SD}=1.53)$. The average of these three elements is 7.41 points $(\mathrm{SD}=4.23)$.

Table 2. Mean $(\overline{\mathrm{X}})$ and Standard deviation (SD), and Intraclass Coefficient Correlation (ICC) of the pretest according to the two raters.

\begin{tabular}{llllllll} 
& \multicolumn{1}{c}{ Rater 1} & \multicolumn{2}{c}{ Rater 2} & \multicolumn{3}{c}{ Mean } & \multicolumn{1}{c}{ ICC } \\
& $\bar{X}$ & SD & $\bar{X}$ & SD & $\bar{X}$ & SD & \\
Grammar and vocabulary $(5 \mathrm{p})$ & 2.52 & 1.41 & 2.30 & 1.40 & 2.41 & 1.37 & 0.909 \\
Pronunciation $(5 \mathrm{p})$ & 3.00 & 1.45 & 2.39 & 1.41 & 2.70 & 1.39 & 0.894 \\
Interactive communication $(5 \mathrm{p})$ & 2.43 & 1.56 & 2.17 & 1.56 & 2.30 & 1.53 & 0.959 \\
TOTAL $(15 \mathrm{p})$ & 7.96 & 4.31 & 6.87 & 4.27 & 7.41 & 4.23 & 0.943
\end{tabular}

Post-test reliability. In Table 3, the results of the post-test show the reliability through the Coefficient Intraclass Correlation (ICC). The ICC values are greater than $80 \%$ (ICC $>0.80)$ in all the indicators, thus is it evident that there is an agreement between the two evaluators. In this way, it is noticed that the level of grammar and vocabulary obtained an average of 3.26 points $(\mathrm{SD}=1.34)$, the level of pronunciation was 3.57 points $(\mathrm{SD}=1.32)$, and the interactive communication indicator was 3.30 points $(\mathrm{SD}=1.40)$. Finally, the sum of averages was 10.15 points $(\mathrm{SD}=4.01)$

Table 3. Mean $(\overline{\mathrm{X}})$ and Standard deviation (SD), and Intraclass Correlation Coefficient (ICC) of the proficiency post-test according to the two raters.

\begin{tabular}{|c|c|c|c|c|c|c|c|}
\hline & \multicolumn{2}{|c|}{ Rater 1} & \multicolumn{2}{|c|}{ Rater 2} & \multicolumn{2}{|l|}{ Mean } & \multirow[t]{2}{*}{ ICC } \\
\hline & $\bar{x}$ & SD & $\bar{x}$ & SD & $\bar{x}$ & SD & \\
\hline Grammar and vocabulary (5 p) & 3.35 & 1.43 & 3.17 & 1.30 & 3.26 & 1.34 & 0.911 \\
\hline Pronunciation $(5 \mathrm{p})$ & 3.65 & 1.27 & 3.48 & 1.44 & 3.57 & 1.32 & 0.885 \\
\hline Interactive communication ( $5 \mathrm{p})$ & 3.48 & 1.41 & 3.13 & 1.46 & 3.30 & 1.40 & 0.898 \\
\hline TOTAL $(15 \mathrm{p})$ & 10.52 & 4.06 & 9.78 & 4.08 & 10.15 & 4.01 & 0.942 \\
\hline
\end{tabular}

Differences between pre and post-test. Table 4 shows the difference between pre-test and post-test. To establish how significant the differences are, two statistical tests were used depending on the distribution of the data: t-Test (normal distribution) and Wilcoxon test (non-normal distribution). Additionally, the significant difference was calculated by the effect size. If this effect size is around 0.01 it is considered as very small, 0.20 small, 0.50 medium, 0.80 large, 1.20 as very large, and 2.0 as huge (Sawilowsky, 2009).

In detail, the table shows the significant increase of the three areas improved on participants after the intervention. The grammar and vocabulary indicator shows an increase of 0.85 points $(z=-3.55, p=0.000$, Cohen's $\mathrm{d}=0.63)$ and a medium effect size. In pronunciation, the increase is 0.87 points $(z=-3.66, p=0.000$, Cohen's $d=$ 
0.64 ) with a medium effect size. Lastly, there is a significant increase of 1.0 point in interactive communication [ $\mathrm{t}$ $(22 \mathrm{gl})=7.23 ; \mathrm{p}=0.000$, Cohen's $\mathrm{d}=0.88$ ] with a large effect size. The overall significant difference shows an increase of 2.74 points on average $(z=-3.66, p=0.000$, Cohen's $d=0.66)$ with a medium effect size.

Table 4. Mean $(\overline{\mathrm{X}})$ and Standard deviation (SD) of the difference between the pre and post-test

\begin{tabular}{llllllll}
\hline & Pretest & \multicolumn{3}{c}{ Posttest } & \multicolumn{3}{c}{ Difference } \\
\cline { 2 - 6 } & $\bar{X}$ & SD & $\bar{X}$ & SD & $\bar{X}$ & SD & \\
Grammar and vocabulary $(5 \mathrm{p})$ & 2.41 & 1.37 & 3.26 & 1.34 & 0.85 & 0.82 & 0.000 \\
Pronunciation $(5 \mathrm{p})$ & 2.70 & 1.39 & 3.57 & 1.32 & 0.87 & 0.81 & 0.000 \\
Interactive communication $(5 \mathrm{p})$ & 2.30 & 1.53 & 3.30 & 1.40 & 1.00 & 1.12 & 0.000 \\
TOTAL $(15 \mathrm{p})$ & 7.41 & 4.23 & 10.15 & 4.01 & 2.74 & 2.65 & 0.000 \\
\hline
\end{tabular}

The data clearly affirm that there is a significant statistical difference between the pre-test and post-test. Comparing the pre-test and the post-test scores, it is evident that the post-test mean $(\bar{X}=10.15)$ is higher than the pre-test score mean $(\bar{X}=7.41)$. Considering the mean and the overall difference, it can be concluded that the difference is in favor of the post-testing. Consequently, these results show a significant overall difference between the students' entry level and their exit level. Participants demonstrated an improvement on speaking, especially in grammar and vocabulary, pronunciation, and interactive communication after using the BDI strategies.

\subsection{Qualitative results}

The qualitative analysis from the participants' perceptions generated seven categories or subcategories which are linked to the central category called Biography Driven Instructional Strategies, BDI strategies. This category is directly associated with the Methodology detached category from which three more subcategories were generated: DOTS Chart, Vocabulary Quilt, and It's All on My Clipboard. These three subcategories correspond specifically to three of the four BDI strategies utilized in this study. The three BDI strategies had an effect on the students' preference which resulted in an additional subcategory called Interest. On the other hand, the Biography Driven Instructional Strategies central category had an academic effect on students' learning regarding the improvement of Listening and Speaking skills which are two more detached categories, labeled with the same names (see Figure $1)$.

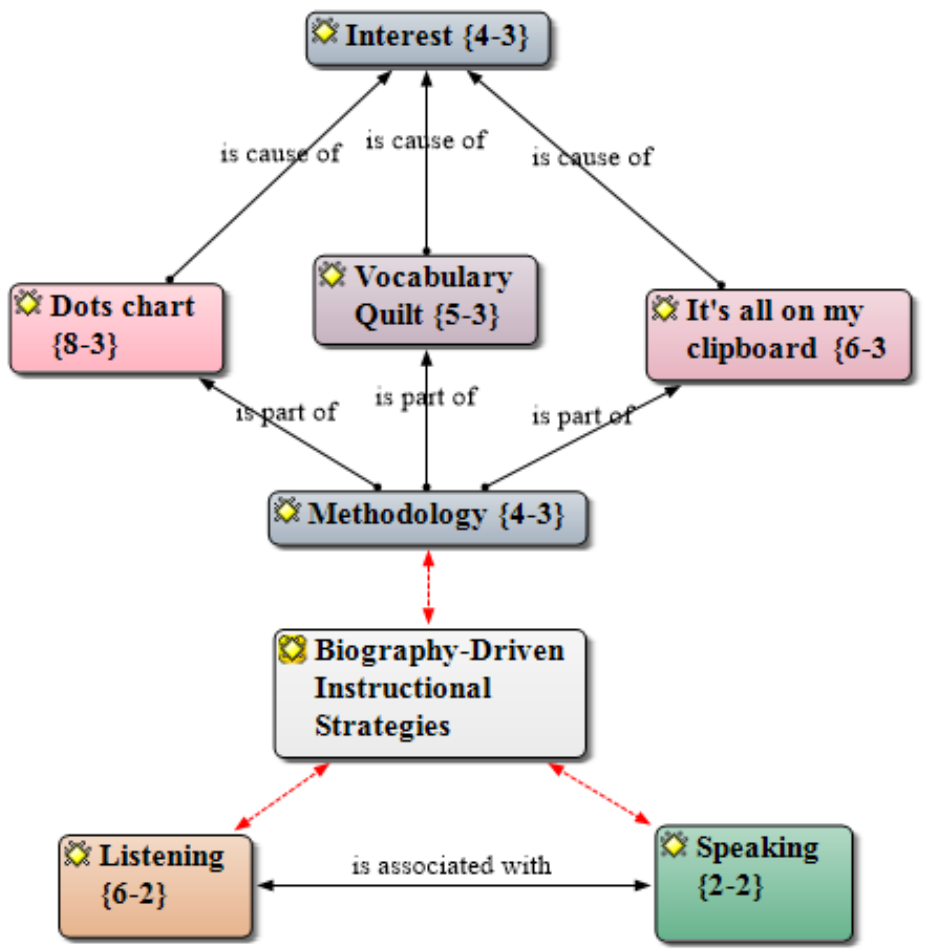

Figure 1. Semantic network of the Biography-Driven Instructional Strategies central category.

The quotes that support the central category are set out below. Each one has been separated in the following order: Methodology $\{4-3\}$, being four the number of citations that supports this detached category and three the number of connections among subcategories, DOTS Chart $\{8-3\}$, Vocabulary Quilt $\{5-3\}$, It's All on My Clipboard $\{6-3\}$, Interest $\{4-3\}$, Speaking $\{2-2\}$, and Listening $\{6-2\}$.

Methodology. One of the main points participants considered remarkable was the methodology used to apply the BDI strategies. The strategies are implemented across three phases of teaching and learning: activation, connection, 
and affirmation (Herrera et al., 2011). This category shows the activities the researcher incorporated throughout the phases in each lesson. Here are the participants' quotes that support this category. They have been identified with the letter $\mathrm{P}$ and their assigned number.

P23: "We use the sticky notes, we draw, we put the meaning and we answered and asked questions concerning the words, and we wrote personal opinions."

P21: "Ehh in each strategy we always had an individual or group work, presentations, oral presentations or interviews."

P23: "I liked the strategy in which we had to write what we knew about the words, what we thought the words could mean using words or pictures. --- English words usually have variations so while writing what we understood we were learning more about the definition and how to use the new words."

P2: "We worked with our classmates who had a good English level, they helped us in oral and individual presentations."

It should be noted that participants identified at least three of the four strategies applied in this study, which have been codified to highlight the relevance they had in their learning process and memory. These strategies specifically are DOTS Chart $\{8-3\}$, Vocabulary Quilt $\{5-3\}$, and It's All on My Clipboard $\{6-3\}$.

DOTS Chart. This section contains what the students expressed in regards to using this BDI strategy. The researcher applied the DOTS Chart strategy with the topic of character and personality traits. To address this topic, it was necessary to teach adjectives which was accomplished through a song about people's qualities which was reported to be an interesting activity for some participants.

P12: "Filling things up and it seemed good because I also had options."

Teacher: "So which of the two would you prefer VOCABULARY QUILT or DOTS Chart?"

P12: "The song."

P14: "I liked the DOTS Chart strategy because we talked about adjectives there."

P21: "The DOTS Chart strategy because the English adjectives topic is something that is widely used and by using them, we learn better from them and their pronunciation, writing and everything."

P4: "I liked the one we used with the topic personality. Using adjectives to describe oneself or other people helped me a lot to learn because I was a little wrong with that topic."

P4: "One of the activities is to describe the personality which helped us to describe people and describe ourselves."

Vocabulary Quilt. This strategy was remembered by several students in which specific procedures of the activities were performed. The topic used for this strategy was healthy and unhealthy habits.

P14: "Ehh an activity that I liked a lot was healthy habits. We ask about food, asking others eh about what they eat for breakfast, lunch. ... The activity I liked the most was the food activity because I could learn a little more from my classmates about what they eat... asking in pairs about breakfast, lunch, and snack ... the oral presentation about food."

P2: "Ehh I liked the theme of food because we interacted with each other since we did an interview. An interview between two classmates and so we were asking and answering."

P21: "An example is when we talked about healthy habits, we made groups and to present to the front what we had worked on our sheets."

It's All on My Clipboard. This strategy had quotes that supported students' memories about the activities that belong to this strategy. This was one of the most delighting strategies for the participants. The topic used for this strategy was festivals and traditions.

P2: "Ehh I liked the strategy of the folder more (It's All on My Clipboard) because with the words we had, we had to get meaning and before we had learned some new words then we could get our definition."

P21: "I also liked the activity of the --- folder because thanks to that we shared more with our classmates, we analyzed what each one thought of each concept and definition of words and the different drawings, we chose one drawing to put same definitions and we shared information."

P23: "I liked the folder one more because I also like English, I also like to draw then to be able to give the definitions, we also gave what we understood about the subject and also because I like to give my opinions and also listen what others say."

P4: "The activity that I liked the most was that of the folder, since with it we share much more with our classmates, giving opinions for both the concepts and to graphically represent the concepts."

P12: "Festivals, that one there was very beautiful among others."

Interest. This subcategory summarizes some quotes, which in general terms refer to the importance of using BDI strategies to learn English. Participants reported that they liked using the strategies in the classroom because they are different tools students have not been familiar with. 
P12: "All strategies because I have not worked like this before, with the papers to complete the things. Good strategies for us who are learning English."

P14: "I liked it a lot because that way I could understand better and I could pronounce most of the words that I did not know before and the strategies helped me a lot with pronunciation in food or adjectives."

P21: "These strategies facilitate learning and the studied topics are easy to help us understand what we see every day as healthy habits and all. Then, we learn vocabulary better."

P4: "I liked the strategy because it is very didactic and helps a lot with the songs and that to pronounce words all that."

Listening. Students pointed out some advantages that allowed them to improve this skill significantly. Most students were allowed to identify the words they heard. This may be seen in the following quotes:

P12: "I have improved a little in listening because I don't understand perfectly, but I already understand a little bit more ehh what you are talking about or what you explain in class and I think that is what I have improved a little more."

P14: "I have learned more listening ...because also thanks to you that everything tell us in English little by little we have been joining what you speak, and little by little also understanding."

P2: "Listening ... because ehh with the songs just as my classmates said ehh I learned to differentiate some words." P21: "Listening and in pronunciation because with the same topic of the songs ehh we had options and by listening to the song we already knew what word can be to complete and we listen to the pronunciation of the words which remains in our head so we learn better."

P23: "I have improved in listening because I know how difficult it is to be able to listen to English words because they have a kind of ... I hear something different from the word so with the songs I have been guiding myself better and being able to listen to the pronunciation too."

P4: "For me, I have improved in listening since with the help of the songs and all the strategies, as well as your classes in English in which you speak only in English, I have increased my level of English a little."

Speaking. These quotes confirm that students consider they have strengthened their speaking skills. Two quotes are related to pronunciation while the other quote is linked to the ability to communicate orally. Although participants did not mention the speaking skill many times, they report that the strategies helped them improve the listening skill as well as pronunciation, which is a speaking subskill.

P14: "And speaking because you insist on teaching the pronunciation, also thanks to the strategies."

P2: "Speaking since you speak a lot in English, we learn and we get involved in speaking English."

P21: "We listen to the pronunciation of the words which remains in our head so we learn better."

\section{Discussion}

This study attempted to investigate the effectiveness of Biography-Driven Instructional strategies on the development of EFL students' speaking skills. The study also sought to examine students' perceptions towards the use of these strategies in the classroom. Both quantitative and qualitative data analysis supported the use of BDI strategies on developing students' speaking skills as they allow students to dig into their background knowledge to connect it to new knowledge, and learn in a safe environment through interactions, group work, discussions, oral presentations, and so on (Herrera et al., 2011).

Results from pre-post speaking tests and a focus group interview revealed the significant effect of the BDI strategies or research-based strategies (Wessels, 2011); DOTS Chart, Vocabulary Quilt, Pictures and Words, and It's All on My Clipboard. The post-test mean score was significantly higher than the pre-test one after implementing the BDI strategies. Results from the speaking tests showed a medium effect size in the criteria of grammar and vocabulary, and in pronunciation. Additionally, a large effect size was demonstrated in the interactive communication indicator. The fact that students improved on these three areas might be attributed to what Perez et al. (2012) mentioned about BDI strategies: they create conditions to use students' interaction to improve comprehension, give opportunities to negotiate the meaning of concepts and academic vocabulary, and let students practice and apply new content and language. Furthermore, when implementing BDI strategies, teachers use "revoicing", especially during the connection phase, which involves listening to what students have to say to then re-uttering their understanding using repetition, rephrasing, expansion, and reporting what has been shared (Forman, Larreamendy- Joerns, Stein, \& Brown, 1998). Such repetition provides students with more routes to participate in academic conversations (Herrera, 2010). Moreover, the application of the BDI strategies resulted in constant participant-participant and instructor-participant conversations due to the planned activities each strategy had. This finding is supported by Murry et al. (2020) who emphasized that BDI strategies are tools to boost classroom conversations, which allow the teacher to connect students' thoughts to the lesson content.

The findings of the study indicated that the three interrelated phases of teaching and learning: activation (before), connection (during), and affirmation (after), which have been tagged as the methodology category, make 
up one pivotal factor that contributed to the improvement of participants' speaking competence. This finding is consistent with MacDonald et al. (2013) who considered that activation, connection, and affirmation (ACA) strategies are beneficial to task engagement since they facilitate the creation of a safe environment that allows students to learn by doing, receiving feedback, and refining their understanding as they gain new knowledge in an interactive way. In addition, the ACA strategies are likely to afford teachers new ways to reinforce and compensate learners' engagement and progress toward learning goals (MacDonald et al., 2013).

The findings also revealed that the BDI strategies helped students recall, learn, and use new words because they were asked to draw or write any prediction about the vocabulary of the lesson (activation phase). Students were able to activate their background knowledge to connect it to the target vocabulary. This finding is aligned to the framework proposed by Herrera et al. (2011) who found that through the activation phase, students record their prior knowledge and experiences to enhance the meaning of words. This finding is also consistent with Wessels (2011) who mentioned that once students have activated their background knowledge, they are able to make "new connections to know words, ideas, and images in their long-term memory" (p.48). Activating students' previous knowledge to learn new vocabulary gave learners the opportunity to have more words to speak in the different communicative activities they were involved in. This is supported by Wang (2014) who found that with some related vocabulary and background information, learners are able to generate more words and ideas in speaking. Moreover, this finding is consistent with Herrera (2010) who affirmed that giving students the opportunity to use words significantly and in different contexts fosters oral language development.

The application of the BDI strategies offered EFL learners valuable opportunities to participate and interact orally in small groups. This was found to be a significant factor to improve students' willingness to speak and share their ideas and personal opinions in a low-risk learning environment. In line with this finding, Wang (2014) and Oradee (2012) found that working in small groups reduces stress and anxiety which promotes students' confidence to communicate orally in English. Regarding low-risk learning environment, Perez et al. (2012) asserted that BDI strategies create conditions for students to have access to a grade-level curriculum, receive support, and be encouraged to use their academic language, no matter what their English proficiency level is. Furthermore, students' speaking abilities increased since they were grouped purposefully considering their linguistic and academic needs and assets which allowed them to receive and provide support while performing collaboratively the planned activities. The BDI model emphasizes the use of group structures, small groups or partners to make students collaborate and learn from one another (Murry et al., 2020). This result was supported by Daif- Allah and Khan (2016) who mentioned that identifying students' needs and interests is key to improve exponentially their speaking ability.

Concerning the performed activities, each BDI strategy has its own multiple activities. The most frequent speaking activities were oral presentations, conversations, interviews, and role plays in front of the class. Those activities were performed mostly in the production stage (affirmation) in which students demonstrated what they have learned using the oral facility. The data from the focus group interview revealed that the afore-mentioned activities led learners to interacting using the spoken language, learning from others, being focused and interested during the class as well as becoming more skillful in the speaking competence. This view is emphasized by Widiati and Cahyono (2006) who considered that classroom activities such as presentations, conversations, role-plays, and discussions are essential to allow interactions and speaking skills improvement. Similarly, this finding is consistent with Ochoa et al., (2016) who concluded that pair work, small groups, role-plays, discussion, and oral presentations are motivating communicative activities that promote English language use. Moreover, Tarabrina (2012) mentioned that instructional activities encouraged interest in the classroom. Lastly, Al-Sobhi and Preece (2018) asserted that instructors should involve learners in classroom activities to foster their speaking competence in conjunction with learner-centered and cooperative learning.

Regarding lessons topics, the researcher utilized the following: personality traits, food, healthy and unhealthy habits, and festivals and traditions. Based on the results, it can be said that participants found these affairs easy and interesting. This finding is aligned to Molina and Briesmaster (2017) who argued that familiar topics make students feel motivated since they have words to speak from their experiences. Additionally, this study found that teachers' discourse, which was delivered in English most of the time, contributed to the improvement of the speaking competence and its pronunciation subskill. The finding is supported by Khan, Khan, Zia-Ul-Islam, and Khan (2017) who indicated that students learned from those teachers who adopted good communication skills to promote students' academic success.

In summary, findings supported previous research about the effect that BDI strategies have on facilitating language learning (Montaño, 2017). Herrera et al. (2011) mentioned that these strategies allow students to develop academic vocabulary through the integration of the four skills: speaking, listening, writing, and reading. However, the results of this study have shown that learners' speaking skill improved significantly after the application of DOTS Chart, Vocabulary Quilt, It's All on My Clipboard BDI strategies. The Pictures and Words strategy was one of the strategies applied in this study; nevertheless, it was not recognized by participants. 


\section{Conclusion}

Herrera and Murry (2015) state that the communicative approach focuses on "learning a language through and for communication" (p.195) by means of authentic purposes. Hymes (1971) sees the communicative competence as a term that has linguistic, explicit and implicit knowledge of grammar rules, and sociolinguistic or contextual knowledge of the rules used in context. When learning a foreign language, mastering speaking is vital because it is the basic skill for communication (Oradee, 2012). However, speaking is one of the most challenging skills to develop in foreign language learning (Leong \& Ahmadi, 2017). Regarding teaching this skill, EFL teachers at the target high school face many constraints when they attempt to develop learners' speaking competence because of the lack of motivation and self-confidence, lack of strategies and activities in textbooks, and limited knowledge of English words. Research has shown that by incorporating some specific activities or learning strategies in the classroom, teachers can address this need. Therefore, this study aimed to evaluate the effectiveness of BDI strategies on EFL learners' oral skill. BDI strategies documented by Herrera et al. (2011) were developed to implement the pedagogical theory of the biography-driven instruction model which supports teachers on their culturally-responsive instruction (Herrera et al., 2012). In addition to what is stated before, the BDI model addresses students' sociocultural, linguistic, cognitive, and academic biographies to ensure their development in the classroom (Herrera, 2010). On the other hand, BDI strategies are social affective, cognitive, and metacognitive tools grounded in a constructivist viewpoint as they scaffold students' knowledge gradually (Herrera et al., 2011 as cited in Montaño 2017). These strategies have been designed for the development of academic vocabulary by integrating reading, listening, writing, and speaking skills (Montaño, 2017). Nonetheless, this case study has demonstrated that students improved their speaking competence after implementing the BDI strategies: Vocabulary Quilt, DOTS Chart, Pictures and Words, and It's All on My Clipboard.

Findings from pre and post-tests indicate that learners improved significantly not only on vocabulary, but also on grammar, pronunciation, and interactive communication. Thus, BDI strategies were effective to develop these sub-skills. It is a well-known fact that these strategies promote academic vocabulary development (Herrera et al., 2011) which allowed participants to learn new words, add them to their repertoire, and used those words to communicate and share ideas using the target language. Additionally, the strategies were beneficial to promote interactive communication since they guide the teacher to group students purposely and scaffold them to assure their active engagement for learning (Herrera et al., 2012). During the implementation of the strategies, students had many opportunities to use English in the classroom due to the fact that they were involved in meaningful interactions. BDI strategies promote self-confidence in learners at any linguistic level to express what they know and succeed in the classroom (Herrera et al., 2012).

Participants' responses from the focus group support existing literature on the positive effects that the implementation of BDI and its related strategies have on improving learner's performance in the classroom. This research suggests that the methodology which incorporates activation, connection, and affirmation phases throughout the lesson cycle, supported students' engagement. These phases were fundamental for students to be active participants, feel motivated, interested, and confident to take part in the following appealing tasks: interviews, role-plays, and oral presentations. All in all, motivation and confidence are key elements to ensure students' progress in the target language (Al-Sobhi \& Preece, 2018). Ultimately, BDI strategies were viewed as effective tools to develop the communicative skill since they assisted the teacher to create a low-risk environment in which students feel safe to participate in the spoken activities using connections of their previous and new knowledge; words, drawings, definitions, and phrases, documented on the strategies. Consequently, the strategies allowed learners to share their knowledge with the teacher and their peers in a supportive classroom ecology.

This research documented the effectiveness of incorporating BDI strategies in the classroom to develop speaking competence. However, it is necessary to recognize its limitations in terms of time. The target institution had many planned events to do throughout the school year. At the beginning of the treatment, classes were interrupted because of these activities which affected the normal application of the strategies throughout the five periods of classes. Occasionally, those five periods were reduced to three. Therefore, it took the researcher more time to finish the implementation of the treatment.

For pedagogical purposes, findings of this study indicate that the BDI model and its related strategies hold a potential support to EFL teachers and learners. BDI assists teachers to meet students' needs by incorporating their biographies in the classroom. It also supports teachers to implement BDI strategies to improve learners' linguistic and academic development. These strategies guide educators to teach differently because the BDI strategies are applied throughout activation, connection, and affirmation stages which have been proved to ensure students' performance in the classroom. EFL teachers should use BDI strategies to overcome the constraints they face when developing speaking in their classes. By implementing BDI strategies suggested in this research, teachers will certainly provide students with opportunities to share their prior and new knowledge actively owing to the fact that learners will have more words to use and as a result, they will be motivated and confident to interact with others. It is also recommended for teachers to plan classes incorporating interesting topics and activities that promote language use. This study obtained valuable results in terms of students' performance in the classroom as well as 
speaking skills improvement. Furthermore, this work gives EFL instructors an opportunity to review different strategies to improve and assess learners' oral production. It is relevant to mention that no study has been conducted before to address the need of developing the speaking competence of EFL learners using BDI strategies in our context. Accordingly, the findings of this case study offer a foundation for future research on developing speaking skills with large classes. Additionally, further studies can be conducted to prove the effectiveness of these strategies on listening, reading, and writing skills. In this study, the researcher used four of the twenty BDI strategies proposed by Herrera, et al. (2011). Future research to integrate the BDI model and other BDI strategies to document their benefits on students' academic success should be carried out.

\section{References}

Afraz, S., Taghizade, L., \& Taghinezhad, A. (2017). The usefulness of pictorial aids in developing female Iranian intermediate EFL learners' speaking proficiency. International Journal of Education and Literacy Studies, 6(1), 38-49. doi: http://dx.doi.org/10.7575/aiac.ijels.v.6n.1p.38

Akkaya, A., Yilmaz, M. Y., \& Aydin, G. (2018). Instructors' views on the assessment and evaluation of the speaking skill in turkish as a foreign language (TFL) classes. International Journal of Progressive Education, 14(5), 130-143. doi: 10.29329/ijpe.2018.157.11

Al-Sobhi, B. M. S., \& Preece, A. S. (2018). Teaching English speaking skills to the Arab students in the Saudi school in Kuala Lumpur: Problems and solutions. International Journal of Education and Literacy Studies, 6(1), 1-11. doi: http://dx.doi.org/10.7575/aiac.ijels.v.6n.1p.1

Askari, K., \& Langroudi, J. (2014). The effectiveness of Ur model in developing Iranian EFL learners' fluency and accuracy in speaking. Journal of Applied Linguistics and Language Research, 1(1), 75-86. Retrieved from: http://www.jallr.com/index.php/JALLR/article/view/6

Bogdan, R. C., \& Biklen, S. K. (2007). Qualitative research for education: An introduction to theory and methods (5th ed). Boston: Allyn \& Bacon.

Brown, H.D. (1994). Teaching by principles: An interactive approach to language pedagogy. Englewood Cliffs, NJ: Prentice Hall Regents.

Burns, A. \& Joyce, H. (1997). Focus on speaking. Sydney: National Center for English Language Teaching and Research.

Calle, A., Calle, S., Argudo, J., Moscoso, E., Smith, A., \& Cabrera, P. (2012). Los profesores de inglés y su práctica docente: Un estudio de caso de los colegios fiscales de la ciudad de Cuenca, Ecuador. Maskana, 3(2), 1-17. https://doi.org/10.18537/mskn.03.02.01

Charmaz, K. (2014). Constructing grounded theory. SAGE publications.

Creswell, J. W. (2014) Research design: Qualitative, quantitative, and mixed methods approaches (4th ED.). Thousand Oaks, CA: SAGE.

Creswell, J. W., \& Guetterman, T. C. (2019). Educational research: Planning, conducting, and evaluating quantitative and qualitative research (6th ed.). New York, US: Person.

Creswell, J. W., \& Plano Clark, V. L. (2018). Designing and conducting mixed methods research (3rd ed.). Thousand Oaks, CA: SAGE.

Creswell, J. W., \& Poth, C. N. (2018). Qualitative inquiry and research design: Choosing among five approaches (4th ed.). Thousand Oaks, CA: SAGE.

Daif-Allah, A. S., \& Khan, M. I. (2016). The impact of open discussion sessions on enhancing the oral communicative abilities of Saudi english language majors at Buraydah Community College. English Language Teaching, 9(6), 108-122. doi: 10.5539/elt.v9n6p108

Dil, Y. (2009). EFL learners 'communication obstacles. Electronic Journal of Social Sciences, 8(29), 84-100. Retrieved from https:/www.acarindex.com/dosyalar/makale/acarindex-1423879078.pdf

Espinosa, L. F., \& Soto, S. T. (2018). Pre-instructional student assessment. MEXTESOL Journal, 42 (4), 1-9. Retrieved from http://www.mextesol.net/journal/index.php?page=journal\&id article $=4438$

Field, A. (2013). Discovering statistics using IBM SPSS statistics (4th ed.). SAGE publications.

Forman, E. A., Larreamendy-Joerns, J., Stein, M. K., \& Brown, C. A. (1998). "You're going to want to find out which and prove it": Collective argumentation in a mathematics classroom. Learning and Instruction, 8(6), 527-548. doi: 10.1016/S0959-4752(98)00033-4

Güvendir, E., Kocabiyik, O. O., \& Dündar, S. (2020). The influence of counsellor trainee support on public speaking and foreign language speaking anxiety in the class setting. International Journal of Psychology and Educational Studies, 7(1), 11-26. doi: http://dx.doi.org/10.17220/ijpes.2020.01.002

Herrera, S. G (2010). Biography-Driven instruction culturally responsive teaching. New York, NY: Teachers College Press.

Herrera, S. G. (2016). Biography-driven culturally responsive teaching (2nd ed.). Teachers College Press.

Herrera, S. G., Holmes, M. A., \& Kavimandan, S. K. (2012). Bringing theory to life: Strategies that make culturally responsive pedagogy a Reality in Diverse Secondary Classrooms. International Journal of Multicultural 
Education, 14(3), 1-19. doi: http://dx.doi.org/10.18251/ijme.v14i3.608

Herrera, S. G., Kavimandan, S. K., \& Holmes, M. A. (2011). Crossing the vocabulary bridge: differentiated strategies for diverse secondary classrooms. New York, NY: Teachers College Press.

Herrera, S. G., \& Murry, K. G. (2015). Mastering ESL/EFL methods: Differentiated instruction for culturally and linguistically diverse (CLD) students (3rd ed.). Pearson.

Hymes, D. H. (1971). On communicative competence. In J. Pride and J. Holmes (Eds.), Sociolinguistics. Penguin, 1972. (Excerpt from the paper published 1971, Philadelphia, University of Pennsylvania Press.)

Jaramillo, M., \& Solano, L. (2019). Youtube english music videos as educational resource to teach vocabulary and improve the listening and speaking skills. In Nuevas tecnologías en el proceso de enseñanza-aprendizaje (pp. 103-106). Universidad Técnica Particular de Loja.

Khan, A., Khan, S., Zia-Ul-Islam, S., \& Khan, M. (2017). Communication Skills of a Teacher and Its Role in the Development of the Students' Academic Success. Journal of Education and Practice, 8(1), 18-21. Retrieved from https://eric.ed.gov/?id=EJ1131770

Koo, T. K., \& Li, M. Y. (2016). A guideline of selecting and reporting intraclass correlation coefficients for reliability research. Journal of chiropractic medicine, 15(2), 155-163. doi: https://doi.org/10.1016/j.jcm.2016.02.012

Leedy, P. D., \& Ormrod, J. E. (2005). Practical research: Planning and design (8th ed.). Upper Saddle River, NJ: Merrill/Prentice Hall.

Leong, L.M.,\& Ahmadi, S.M. (2017). An analysis of factors influencing learners' English Speaking skill. International Journal of Research in English Education, 2(1), 34-41. Retrieved from https://www.sid.ir/en/journal/ViewPaper.aspx?ID=520992

Lyons, E., \& Coyle, A. (2007). Analysis of qualitative data in psychology. London: Sage.

MacDonald, G. L., Miller, S. S., Murry, K., Herrera, S., \& Spears, J. D. (2013). Efficacy of ACA strategies in biography-driven science teaching: An investigation. Cultural Studies of Science Education, 8(4), 889-903. doi: $10.1007 / \mathrm{s} 11422-013-9517-4$

Molina, M., \& Briesmaster, M. (2017). The Use of the 3/2/1 technique to foster students' speaking fluency. Inquiry in education: 9 (2). Retrieved from: https://eric.ed.gov/?id=EJ1171669

Montaño, J. (2017). Learning strategies in second language acquisition. US-China Foreign Language, 15 (8), 479492. doi: $10.17265 / 1539-8080 / 2017.08 .001$

Moreira, W., Fontaines-Ruiz, T., \& Soto, S. (2017). Enhancing International baccalaureate students' speaking ability through oral presentations. International Teacher Education Conference - ITEC. United States: Cambridge Massachusetts. Retrieved from https://www.researchgate.net/publication/321478484_Enhancing_International_Baccalaureate_Students_Sp eaking_Ability_Through_Oral_Presentations

Murry, K. G., Holmes, M., \& Kavimandan, S. K (2020). Approximating Cultural Responsiveness: Teacher Readiness for Accommodative, Biography-Driven Instruction. In FIRE: Forum for International Research in Education, 6 (2), 103-124. Retrieved from https://eric.ed.gov/?id=EJ1248095

Nunan, D. (2003). Designing tasks for the communicative classroom. Cambridge Universit Press.

Ochoa, C., Cabrera, P., Quiñónez, A., Castillo, L., \& González, P. (2016). The effect of communicative activities on efl learners' motivation: A case of students in the amazon region of ecuador. Colombian Applied Linguistics Journal, 18(2), 39-48. doi: DOI: http://dx.doi.org/10.14483/calj.v18n2.10018

Oradee, T. (2012). Developing speaking skills using three communicative activities (discussion, problem-solving, and roleplaying). International Journal of Social Science and Humanity, 2(6), 533-535. http://dx.doi.org/10.7763/IJSSH.2012.V2.164

Perez, D., Holmes, M., Miller, S., \& Fanning, C. (2012). Biography-driven strategies as the great equalizer: Universal conditions that promote K-12 culturally responsive teaching. Journal of Curriculum and Instruction, 6(1), 25-42. doi: https://doi.org/10.3776/joci.\%25y.v6i1p25-42

Sawilowsky, S. S. (2009). New effect size rules of thumb. Journal of Modern Applied Statistical Methods, 8(2), 597-599. doi:10.22237/jmasm/1257035100

Soria, B. R., \& Iza, S. J. (2019). Task-based learning approach in the development of the speaking skill (Master's thesis). Retrieved from https://repositorio.uta.edu.ec/jspui/handle/123456789/29810

Tarabrina, I. (2019). Addressing idiom avoidance in culturally and linguistically diverse students through biography-driven instruction (Doctoral dissertation, Kansas State University). Retrieved from https://krex.kstate.edu/dspace/handle/2097/40220

Wang, Z. (2014). Developing accuracy and fluency in spoken english of Chinese EFL learners. English language teaching, 7(2), 110-118. doi:10.5539/elt.v7n2p110

Wessels, S. (2011). Promoting vocabulary learning for English learners. Reading Teacher, 65(1), 46-50. https://doi.org/10.1598/RT.65.1.6

Widiati, U., \& Cahyono, B. Y. (2006). The teaching of EFL speaking in the Indonesian context: The state of the 
art. Bahasa dan seni, 34(2), 269-292. doi: 10.17977/jip.v13i3.40

Woolf, N. H., \& Silver, C. (2017). Qualitative analysis using ATLAS.ti: The Five-Level QDATM Method. Routledge.

1. What's your name? How do you spell that?

Appendix A

Pre- test Questions

2. How old are you?

3. Where do you live? What do you like about living in...?

4. What is your favorite activity?

5 . What do you do on the weekends?

6 . Where do you study?

7. What subjects do you like best at school?

8 . What did you do yesterday evening?

Appendix B

Post-test Questions

1. Can you tell me what your full name is?

2. How are you doing today? How are you?

3 . Where do you come from? Where are you from?

4. Tell me something about: Your favorite sport

5. What food don't you like?

6 . What's the name of your school?

7. What are your favorite subjects?

8. What do you do after school?

Appendix C

Rubric for Pre-Post Tests

\begin{tabular}{|l|l|l|l|}
\hline A2 & Grammar and Vocabulary & Pronunciation & Interactive Communication \\
\hline 5 & $\begin{array}{l}\text { Shows a good degree of control of simple } \\
\text { grammatical forms. Uses a range of } \\
\text { appropriate vocabulary when talking } \\
\text { about everyday situations. }\end{array}$ & $\begin{array}{l}\text { Is mostly intelligible, and has some } \\
\text { control of phonological features at both } \\
\text { utterance and word levels. }\end{array}$ & $\begin{array}{l}\text { Maintains simple exchanges. Requires } \\
\text { very little prompting and support. }\end{array}$ \\
\hline 4 & $\begin{array}{l}\text { Shows sufficient control of } \\
\text { simple grammatical forms. Uses } \\
\text { appropriate vocabulary to talk about } \\
\text { everyday situations. }\end{array}$ & $\begin{array}{l}\text { Performance shares features of Bands 3 and 5. } \\
\text { control of phonological features. }\end{array}$ & $\begin{array}{l}\text { Maintains simple exchanges, despite } \\
\text { some difficulty. Requires prompting } \\
\text { and support. }\end{array}$ \\
\hline 3 & $\begin{array}{l}\text { Shows only limited control of a few } \\
\text { grammatical forms. Uses a vocabulary of } \\
\text { isolated words and phrases. }\end{array}$ & $\begin{array}{l}\text { Has very limited control of phonological } \\
\text { features and is often unintelligible. }\end{array}$ & $\begin{array}{l}\text { Has considerable difficulty maintaining } \\
\text { simple exchanges. Requires additional } \\
\text { prompting and support. }\end{array}$ \\
\hline 1 & \multicolumn{2}{|c|}{\begin{tabular}{l} 
Performance below Band 1. \\
\hline 0
\end{tabular}}
\end{tabular}

Source: Assessment scales A2 Key for Schools Speaking. Retrieved from https://www.cambridgeenglish.org/Images/168174-cambridge-english-key-for-schools-handbook-forteachers.pdf 
Appendix D

Interview Protocol

Focus Group Interview

Interview Protocol

Developing Speaking Skills on EFL Learners through Biography-Driven Instructional Strategies

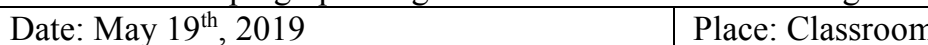

\begin{tabular}{|l|l}
\hline Interviewer: the researcher & Interviewee: Six participants
\end{tabular}

Instructions:

Make sure you respond honestly.

There are no right or wrong answers.

Feel free to speak up.

Listen to the questions carefully.

Each participant should respond each question

The interview will be held in the participants' native language.

The interview will be held in a discussion fashion.

Questions:

1. ¿Cuál es su opinión sobre las estrategias implementadas durante estos meses?

2. ¿Qué estrategia le gusto más? Por qué?

3. ¿En qué área considera que ha mejorado con el uso de las estrategias y actividades realizadas?

4. Mencione algunas actividades realizadas en clase durante estos meses.

5. ¿Qué actividad o actividades le gusto más? ¿Por qué?

Muchas gracias por su participación y colaboracion en el desarrollo de esta entrevista.

Source: Creswell (2014)

Appendix E

Consentimiento Informado

Información del Participante:

Por favor, marque la categoría a la que aplica.

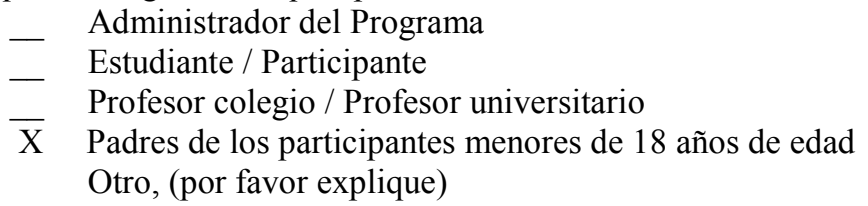

Yo, representante legal del estudiante , autorizo que mi representado participe en el proyecto de investigación coordinado por María Luisa Vire Quezada, cuya finalidad es construir conocimiento con respecto al desarrollo de la destreza del habla. Este estudio forma parte del trabajo de titulación de la Maestría en Lingüística Aplicada a la Enseñanza del Idioma Inglés.

\section{Propósito del estudio de investigación}

El propósito del presente estudio de investigación es evaluar la influencia de estrategías basadas en biografía sobre la destreza del habla.

\section{Descripción de los métodos de investigación}

Los métodos y técnicas de investigación que serán usadas en este estudio son: pretest (prueba pre-tratamiento), postest (prueba post tratamiento), y grupo de enfoque para entrevista.

\section{Requisitos de los participantes}

Participarán estudiantes entre 15 y 17 años de edad que estén cursando el Segundo Año de Bachillerato y en su formación académica reciban la materia de Inglés ( 5 horas semanales), también deberán entregar el acta formal de consentimiento aceptando su participación en el proceso de investigación.

Los participantes responderán un pre-test que medirá su destreza de habla, además serán parte del grupo focal de entrevista que permitirá conocer sus impresiones sobre el proyecto de investigación. Finalmente, desarrollarán un pos-test que evaluará su progreso cuantitativo.

La docente desarrollará su estudio con la autorización y supervisión de las autoridades del establecimiento educativo. 


\section{Beneficios para los participantes}

Al formar parte del proyecto de investigación, los participantes fortalecerán sus habilidades del habla, consecuentmente, incrementarán su nivel comunicativo en el idioma inglés como lengua extrajera.

\section{Riesgos y molestias}

El único riesgo previsible para el participante es el tiempo para hacer la entrevista, el mismo que no será más de una hora. Por favor, comunicarse con la investigadora María Luisa Vire Quezada, 098785956, correo electrónico marialuisavire0409@gmail.com

\section{Confidencialidad}

La información que mi representado aporte en esta investigación será legal y confidencial. Durante las publicaciones que resulten del presente estudio no se incluirán su nombre o dirección así como ninguna información social o personal.

\section{Participación voluntaria}

La participación en este estudio es voluntaria. Entiendo y soy libre de retirar mi consentimiento para que mi representado participe en este proyecto u otras actividades investigativas. Se me ha dado la oportunidad de hacer preguntas sobre la investigación y he recibido respuestas satisfactorias. Los datos que proveo en este estudio permanecerán anónimos. Al firmar este formulario de consentimiento manifiesto que entiendo los términos asociados con la investigación. Consiento voluntariamente que mi representado participe en este estudio.

Firma del Representante Source: adapted from Moreira, Fontaines-Ruiz and Soto (2017)

\section{Fecha}

